\title{
Clinical properties of a novel, glistening-free, single-piece, hydrophobic acrylic IOL
}

This article was published in the following Dove Press journal:

Clinical Ophthalmology

2I February 20I4

Number of times this article has been viewed

\author{
Mark Packer' \\ Mohan Rajan ${ }^{2}$ \\ Edoardo Ligabue ${ }^{3}$ \\ Peter Heiner ${ }^{4}$ \\ 'Oregon Health and Science \\ University, Portland, OR, USA; ${ }^{2}$ Rajan \\ Eye Care Hospital Pvt Ltd, Chennai, \\ India; ${ }^{3}$ Ophthalmology Department, \\ Centro Diagnostico Italiano, Milan, \\ Italy; ${ }^{4}$ Bond University Medical School, \\ Robina, QLD, Australia
}

\begin{abstract}
A new, single-piece, hydrophobic acrylic lens - the first constructed with a lens optic and haptics comprised of a hydroxyethyl methacrylate-polyethylene glycol phenyl ether acrylate-styrene copolymer, cross-linked with ethylene glycol dimethacrylate, and labeled as "glistening-free" - was recently introduced globally. Glistenings have been a significant source of clinical concern with previous hydrophobic lens designs. This new monofocal lens provides enhanced, clear optics for lens-based surgery. The superior optical clarity of this lens is achieved through the elimination of glistenings, enhanced surface durability, high refractive index, a high Abbe number, and an aspheric design. Additionally, the lens design reduces the risk of developing posterior capsule opacification.
\end{abstract}

Keywords: glistenings, monofocal hydrophobic acrylic, IOL, aspheric

\section{Background}

Today's cataract surgery commonly involves phacoemulsification with the implantation of an intraocular lens (IOL) in the capsular bag. There are numerous types of IOLs that can be used after cataract extraction, including monofocal, multifocal, accommodating, and toric designs.

Reducing any potential postoperative complications (such as posterior capsule opacification [PCO], a dislocated lens, cystoid macular edema, or endophthalmitis) will help surgeons meet increasing demands for their services from an aging population.

Several types of IOL materials and designs are in use today, including hydrophobic acrylic, hydrophilic acrylic, silicone, and polymethylmethacrylate materials; aspheric and nonaspheric, anterior chamber and posterior chamber, one-piece or three-piece, and in-the-bag or sulcus-fixated designs.

Hydrophobic acrylic IOLs were designed to prevent hydration from entering into the lens after implantation and are the most commonly used lens material. ${ }^{1}$ These lenses are known for their intraocular stability; Mentak suggested that hydration to equilibrium plays a role in this stability. ${ }^{2}$ Early reports of calcification and opacification plagued hydrophilic acrylic IOLs and prevented mass acceptance. ${ }^{3}$ Silicone IOLs, while acquiring a reputation for resisting PCO, have been associated with a three-fold increased risk of serious infection when compared to acrylic IOLs. ${ }^{4}$ Further, silicone IOLs are not recommended for implantation in high myopes because of the greater risk of vitreoretinal pathology and the need for silicone oil in these eyes. ${ }^{5}$

Biocompatibility is often a point of discussion with IOL materials, with anterior capsule opacification, $\mathrm{PCO}$, and capsule contraction comprising the main components of capsular biocompatibility. ${ }^{6} \mathrm{PCO}$ is the most common complication of cataract
Correspondence: Mark Packer

777 South Flagler Drive, Suite I700-W,

West Palm Beach, FL 3340I, USA

Tel + I 54| 915 029|

Fax + I 8888409392

Email mark@markpackerconsulting.com 
surgery ${ }^{7}$ affecting vision. Sharp-edged IOLs demonstrate a lower incidence of $\mathrm{PCO}, 8,9$ and continuous 360-degree square edges are significantly better than square edges interrupted at the optic-haptic junction. ${ }^{10}$ Polymethylmethacrylate IOLs have been reported to have higher levels of PCO than either acrylic or silicone IOLs. ${ }^{11}$

Werner defined glistenings as "fluid-filled microvacuoles that form within the IOL optic when the IOL is in an aqueous environment." ${ }^{12}$ Glistenings have been reported primarily in hydrophobic acrylic lenses. ${ }^{13-19}$ In some cases, glistenings have led to explantation or IOL exchange. ${ }^{12,19}$ To date, there is only one single-piece hydrophobic acrylic IOL (enVista ${ }^{\mathrm{TM}}$, Bausch and Lomb Incorporated, Rochester, NY, USA) comprised of materials clinically proven to be glistening-free. ${ }^{20,21}$

As long as monofocal IOLs remain the primary lens of choice, surgeons are most likely to choose those lenses that are easiest to implant, have the fewest unwanted visual side effects (thereby improving patient outcomes), and have been shown to be biocompatible and safe. We therefore have undertaken a review of the literature to provide an analysis of the advantages and disadvantages of the enVista lens and to stimulate an open discussion about monofocal IOLs.

\section{Unique characteristics of the enVista lens}

The enVista is a single-piece, hydrophobic, square-edged, posterior chamber acrylic lens designed to offer an additional benefit for cataract surgeons in that it has been approved as "glistening-free". ${ }^{20}$ Numerous high-quality lenses are currently marketed, and the advantages of each have been published. . $^{2,22-28}$

There are no reports in the literature of hydrophobic lenses calcifying, and the incidence of PCO is lower in hydrophobic than in hydrophilic lenses (it has been reported in up to $43 \%$ of eyes implanted with a polymethylmethacrylate IOL). ${ }^{7}$ While the square-edged lenses in general have a lower incidence of PCO than rounded-edged IOLs, ${ }^{8}$ both hydrophobic acrylic square-edged lenses and silicone squareedged lenses have proven superior to hydrophilic acrylic square-edged lenses. ${ }^{24}$

The harder surface of hydrophobic lenses and the higher level of surface stability may render them more suitable for toric or multifocal iterations than other materials. ${ }^{2}$ Similarly, single-piece hydrophobic acrylic IOLs have shown excellent rotational stability, adding to the evidence that this type of lens is suitable for a toric version. ${ }^{28}$ The enVista lens was designed with fenestration holes to prevent torsion from capsular bag contraction.

The enVista lens has a much higher surface hardness than other hydrophobic IOLs, making it the least susceptible to abrasions and creases resulting from forceps or other instrumentation. ${ }^{20}$

The amount of fluid in a lens - or the amount of fluid a lens will accept after implantation - can play a role in the generation of glistenings, which can be prevented by using polymers designed for prehydration to equilibrium. ${ }^{21}$ In the enVista, the polymer is a crosslinked copolymer of aliphatic and aromatic acrylic monomers (Figure 1). This particular IOL is purposely engineered with hydrophilic sites for specific water binding, optimizing its water content. ${ }^{22}$ This planned set of binding sites prevents the development of water-filled vacuoles typically responsible for the onset of glistenings. ${ }^{21}$

Functional vision, or how vision relates to quality of life (eg, reading newsprint, night driving), is directly impacted by the amount of aberrations in an eye. ${ }^{29}$ Contrast sensitivity is a potent indicator of a patient's functional vision, and eyes with aberrations will have reduced contrasted images on the retina. ${ }^{27}$ Guirao et al ${ }^{30}$ suggested conventional IOLs may be unable to compensate for corneal aberrations. Additionally, aspheric IOLs have been shown to offer better functional vision than spherical IOLs, ${ }^{25,31-34}$ but some find the differences subtle because of variations in pupil size, IOL tilt and decentration, and whether the asphericity of the IOL was matched to the patient's cornea. Ligabue and Giordano found the enVista produced a low coma value, indicating good centration within the capsular bag and neutral internal longitudinal spherical aberration. ${ }^{35}$

Functional vision can be improved by reducing residual spherical aberration present in the pseudophakic eye. While it is possible to measure the asphericity of the cornea preoperatively and select a lens based on a "target" spherical aberration (SA), this is not the current standard of practice of most cataract surgeons. The enVista IOL is neutral with respect to spherical aberration, neither adding nor subtracting to the spherical aberration of the postoperative eye. ${ }^{36}$ This makes it particularly suitable for use in developing countries where a sophisticated preoperative workup may not be available; see Figure 2.

\section{Glistening-free modality}

Glistenings vary in size and start to appear anywhere from a few months after surgery up to 1 year, but usually not beyond that time frame. Numerous studies have evaluated glistenings in hydrophobic acrylic lenses, as the disturbance tended to 


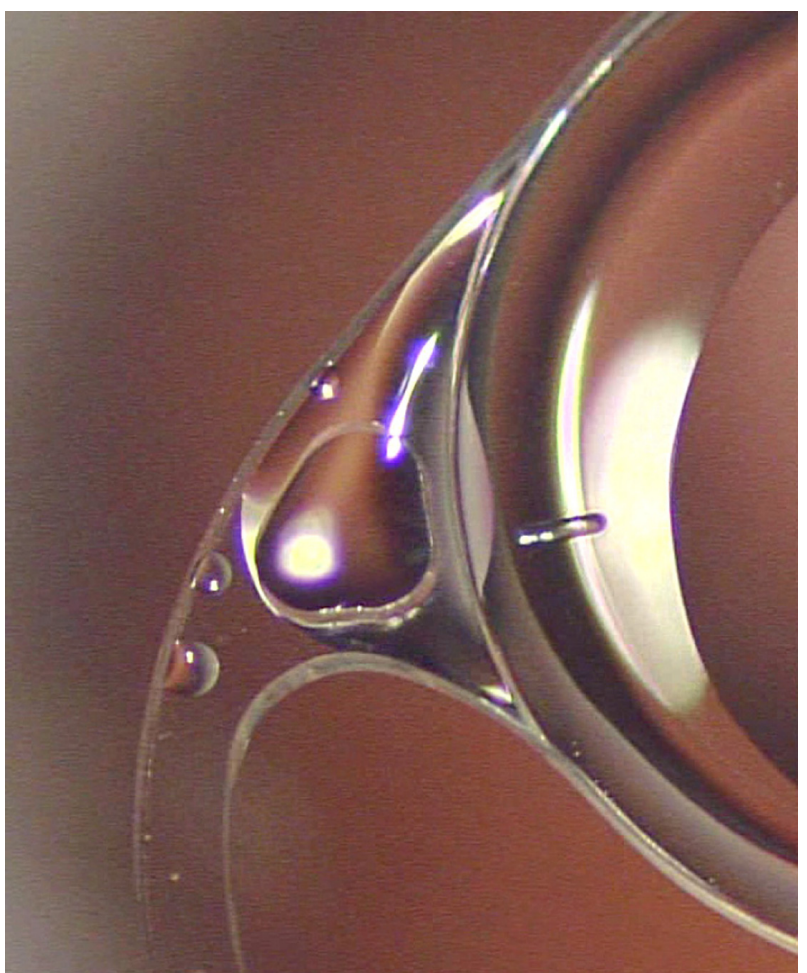

Figure I The haptics and a part of the optic plate design of an enVista ${ }^{\mathrm{TM}}$ toric IOL (Bausch and Lomb Incorporated, Rochester, NY, USA), which is also a monofocal lens. The linear marks are the reference points for the $\mathrm{OOL}$ orientation.

Note: Images courtesy of E Ligabue.

Abbreviation: IOL, intraocular lens.

occur most often in the AcrySof ${ }^{\circledR}$ (Alcon Laboratories, Inc., Fort Worth, TX, USA) line of IOLs. ${ }^{13-18,21}$ Figure 3 shows an example of glistenings on an AcrySof lens. Glistenings occur because the swollen polymer network eventually decomposes, leading to the microvacuole formation..$^{16,37-42}$ These microvacuoles, in turn, produce backscatter, which may adversely impact functional vision. While visual acuity is not always affected, contrast sensitivity may be. ${ }^{13,17}$ Certain systemic diseases (such as diabetes) and certain ocular diseases (such as glaucoma ${ }^{15}$ and uveitis ${ }^{12}$ ) may increase the likelihood of developing glistenings. The phenomenon is unexpectedly higher in African American and Asian patients. ${ }^{43}$

The phenomenon seems to be more common and seems to increase over time in blue light-filtering specific hydrophobic acrylic IOLs more than in other material designs (Figure 3 ).${ }^{16}$ Colin et al described a very high incidence of glistenings ( $87.4 \%$ ), with almost $50 \%$ of the IOLs affected graded as the more severe grade $2 ;{ }^{16}$ the study also suggested the severity of glistenings may be related to the IOL power selected. Thinner lenses (lower dioptric powers) seem to be less likely to develop glistenings than their

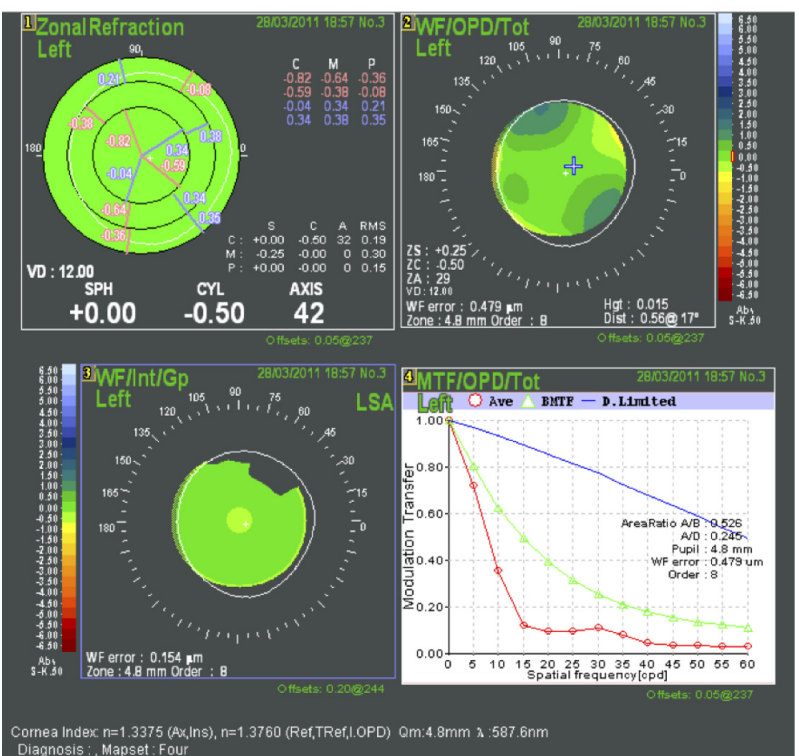

Figure 2 The enVista ${ }^{\mathrm{TM}}$ IOL (Bausch and Lomb Incorporated, Rochester, NY, USA) produces neutral spherical aberration, as seen in this example.

Note: Images courtesy of E Ligabue.

Abbreviation: IOL, intraocular lens.

thicker counterparts. ${ }^{15}$ Christiansen previously suggested that greater severity levels of glistenings would also result in significantly greater decreases in visual acuity compared to lower levels of glistenings. ${ }^{13}$

It is likely that the impact of glistenings on functional vision may have been underdiagnosed and may be much more common than previously thought, even when the Snellen acuity remains acceptable or unchanged. ${ }^{15}$ Recently, the International Society for Intraocular Lens Safety has recommended all IOL manufacturers include a description of glistenings on packaging to widen surgeon awareness. ${ }^{44}$

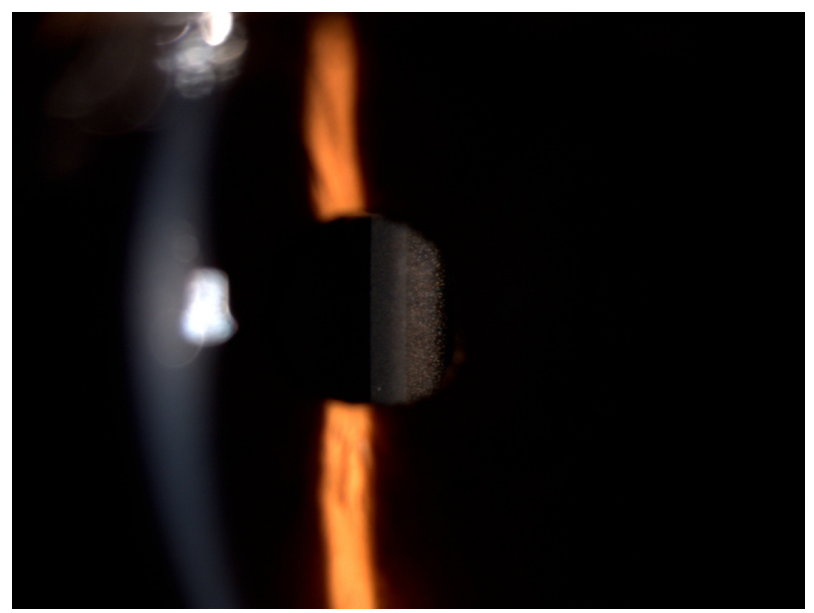

Figure 3 An example of glistenings found on the AcrySof (Alcon) yellow-tinted lens at 6 months postoperatively.

Note: Image courtesy of E Ligabue. 
The enVista lens has eliminated the issue of glistenings by virtue of both its high water content, its material design, and its packaging. ${ }^{20-22,37}$ The enVista lens is packaged in a $0.9 \%$ sterile solution that helps ensure the lens neither gains nor loses hydration. ${ }^{22}$ The stable surface morphology and high refractive index (1.54) remain intact even after hydration; ${ }^{21}$ Miyata had previously shown that water content fluctuations are directly related to glistening formation. ${ }^{37}$ According to the Directions for Use with the lens,

[...] testing established that glistenings were eliminated by a change in the IOL hydration solution from $10.0 \%$ saline to $0.9 \%$ saline. This was confirmed in an additional clinical trial conducted outside of the United States. ${ }^{21}$ In this study, 172 eyes of 142 patients were examined at least once between 1 and 6 months, and 123 eyes of 101 patients were examined at least once between 6 months and 2 years. No glistenings were observed at any time. ${ }^{36}$

enVista ${ }^{\circledR}$ Product Insert. Copyright $\odot 2012$ Bausch \& Lamb Incorporated. Used with permission of Bausch \& Lamb Incorporated.

The individual packaging (sterilized via gamma irradiation) also may play a part in the lens' ability to eliminate long-term water exchange.

\section{Optics and quality of vision}

The enVista IOL is aspherically neutral and has an ultraviolet blocker. ${ }^{24,27}$ Advantages of this configuration include maintaining the postsurgical contrast sensitivity at healthy levels, having no increase in spherical aberrations, and enhancing depth of field. The aspheric design also ensures a uniform distribution of dioptric power throughout the lens from center to edge. The lens is biconvex with equal front and back asphericity; therefore, the effect of the inherent individual aberrations in the cornea remains unchanged. ${ }^{23,35}$

Disadvantages of this configuration include the inability to mimic a natural lens' optic system. However, Altmann et $\mathrm{a}^{45}$ showed that an aspheric IOL designed to have low or insignificant inherent spherical aberration would not be affected by decentration.

Similarly, the advantages and disadvantages of blue-light filtering IOLs have been thoroughly discussed. ${ }^{16,46-50}$ Briefly, there is no direct evidence supporting the theory that these types of IOLs are neuroprotective against certain retinal disorders. $^{51}$

\section{Reducing PCO}

PCO has a deleterious effect on a patient's vision and is caused by an abundance of lens epithelial cells (LECs) that cause fibrotic changes and posterior capsule wrinkling. PCO remains the most frequent complication of cataract surgery. A round edge design cannot prevent LECs from migrating behind the lens; the sharper the edge, the more successful it is at inhibiting this LEC migration. ${ }^{24}$

Nishi was the first to suggest the risk of PCO can be diminished with lenses that have a 360-degree square posterior edge, with the caveat that the edge needed to remain in constant contact with the capsular bag. ${ }^{8}$ Tetz et al first described an evaluation of posterior capsule opacification (EPCO) software in 1997 that allows clinicians to score PCO. ${ }^{52}$ EPCO is a "morphologic assessment of PCO in which the geographical extent and density of backscatter on retroilluminated images determine the overall EPCO score". 52 Individual scores (on a 5-point scale of 0-4) are calculated by multiplying the opacification grade by the fraction of the affected capsule area behind the IOL optic. Generally, a score of 2 or above indicates a significant PCO and a need for Nd:YAG capsulotomy.

Tetz and Wildeck have suggested the edge must be "defined as the deviation from an ideal rectangular projection." ${ }^{53}$ Within those parameters, edge designs that successfully prohibit cell growth are characterized by an area above the edge that measures $13.5 \mu \mathrm{m}^{2}$ at most. ${ }^{53,54}$ Werner et al used AutoCAD software (Autodesk, Inc., Mill Valley, CA, USA) to measure the deviation from an ideal square edge on 16 hydrophobic or silicone IOLs and found large variations from $4.8-338.4 \mu \mathrm{m}^{2}$ on a $40 \mu \mathrm{m}$ reference circle to $0.2-524.4 \mu \mathrm{m}^{2}$ on a $60 \mu \mathrm{m}$ reference circle. ${ }^{54}$ The overall variations for acrylic IOLs have been found to range from $69.5-338.4 \mu \mathrm{m}^{2}$ and for silicone IOLs to range from $4.8-281.4 \mu \mathrm{m}^{2}$ on a $40 \mu \mathrm{m}$ reference circle. ${ }^{47}$ Nanavaty used scanning electron microscopy to evaluate 17 IOLs and found all the hydrophilic acrylic IOLs had a radius of curvature greater than $10.0 \mu \mathrm{m}$ with one exception; all hydrophobic acrylic IOLs had a radius of curvature less than $10.0 \mu \mathrm{m}$, with one exception. ${ }^{24} \mathrm{In}$ that study, the Bausch and Lomb SofPort Advanced Optics IOL had the sharpest posterior optic edge profile. There is some suggestion that a tumble polish on the lens may smooth the edges, reducing the square-edge advantage in preventing PCO. ${ }^{24}$

Additional studies have suggested that the gap in a sharp posterior edge that occurs in some designs at the haptic-optic junction of a single-piece acrylic lens may contribute to the cell ingrowth along the haptics (the Achilles heel effect), but study results remain mixed..$^{55}$ Becker et al further suggested wide haptic roots may prevent the 
capsular bending process, ${ }^{55}$ and Nishi et al reported narrow haptics were superior to wider haptics. ${ }^{56-58}$ What seems to be uniform is that uninterrupted edges are more beneficial at preventing PCO. ${ }^{10}$ The enVista uses a continuous square edge to prevent lens epithelial cell migration. ${ }^{22}$

\section{Initial observations: implantation techniques and short-term outcomes}

Per the Directions for Use, optimal implantation for the enVista is through a $2.6 \mathrm{~mm}$ incision with in-the-bag implantation. ${ }^{36}$ The US pivotal study results showed $100 \%$ of subjects achieving a corrected distance visual acuity of $20 / 40$ or better at $4-6$ months - and $84.3 \%$ achieved $20 / 20$ or better. ${ }^{20}$ No glistenings were reported at any follow-up time point. ${ }^{20}$ The mean evaluation of PCO score at 6 months as measured with EPCO software was $0.032 \pm 0.101$. These results were similar to those found outside the US during a 2-year study. ${ }^{21}$

In a smaller study, ${ }^{35} 30$ patients undergoing uneventful cataract surgery with the enVista through a $2.2 \mathrm{~mm}$ incision were followed for 2 years to evaluate subjective and objective visual quality and optical image quality. Figure 2 shows a typical postoperative outcome. In all cases, patients had good visual quality as measured by the OPD-Scan III (NIDEK Co, Ltd, Gamagori, Japan) (evaluating internal longitudinal spherical aberration, internal coma, modulation transfer function, and total point spread function, all at a $4.5 \mathrm{~mm}$ pupil diameter). The internal longitudinal spherical aberration was neutral, and the mean best corrected visual acuity was 0.987 (decimal fraction) with a spherical equivalent of $-0.74 \mathrm{D}$. The internal low coma value (mean value $0.032 \mu \mathrm{m}$ ) equates to good centration within the capsular bag.

The authors can confirm no complaints of edge glare or negative dysphotopsia in their series of cases to date. Further, none has observed glistenings or found any significant PCO. There have been no complaints of dysphotopsia, positive or negative, to date (M Rajan, P Heiner, personal communication, December 2012), despite the square edge and relatively high refractive index. The absence of dysphotopsia may be a characteristic of the material, although the mechanism awaits further elucidation and confirmation. The lens remains well centered after implantation (Figure 4); however, slight decentration does not adversely impact the performance. $^{23}$

Anecdotally, a $2.2 \mathrm{~mm}$ wound assist approach to implantation can be equally successful, but a $1.8 \mathrm{~mm}$ incision is too

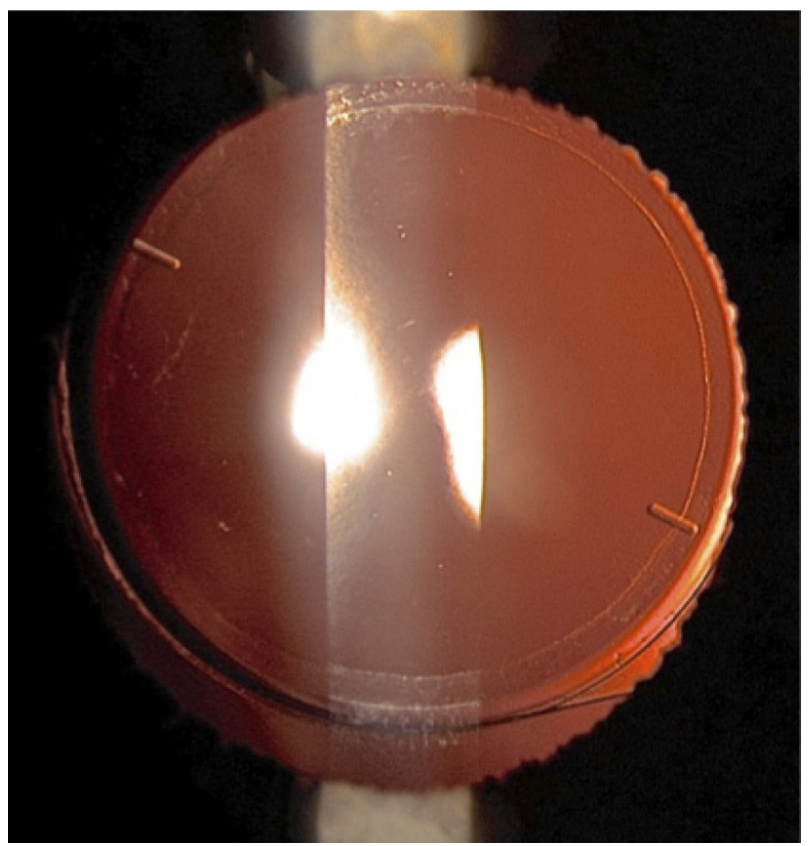

Figure 4 The enVista provides good centration. Here, the capsulorhexis was performed by the VICTUS ${ }^{\mathrm{T} M}$ Femtosecond Laser Platform (Bausch and Lomb Incorporated, Rochester, NY, USA) for cataract surgery and is almost perfect in circularity. Note: Image courtesy of E Ligabue.

small, considering the injector and implantation approach (P Heiner, E Ligabue, personal communication, December 2012). Despite the hardness of the material, the lens is capable of undergoing compression in an injection device to permit implantation through what is commonly referred to as a microincision.

This lens, while a viable option for the majority of patients, is not recommended for all cataract patients; we do not believe those with a high degree of spherical aberrations would benefit. Likewise, if the capsule bag breaks during surgery, this lens, like other single-piece acrylic IOLs, should not be implanted in the sulcus. ${ }^{59}$

To date, the quality of vision of this lens has not been directly compared to any other currently marketed lens. Similarly, the rates of $\mathrm{PCO}$ for this lens have not been compared to other lenses, in part because there are limited long-term data available for the enVista lens, and PCO may take years to develop after IOL implantation. ${ }^{60}$ The authors believe further, longer-term studies are warranted to address these issues.

\section{Conclusion}

The enVista IOL is a new single-piece hydrophobic acrylic lens that is the only IOL to be granted US Food and Drug Administration approval as having a material with no glistenings of any grade reported for any subject during clinical studies. The lens has shown a high degree of bioadhesion, which 
has been confirmed by its high degree of rotational stability after implantation. ${ }^{61}$ The surface hardness and rigidity of the lens provide an extra level of protection against deformation that other lenses do not provide. These advantages make enVista highly desirable to surgeons, patients, private insurance companies, and health care agencies.

\section{Acknowledgments}

Michelle Dalton, ELS, provided writing assistance, funded by Bausch and Lomb, for this manuscript. Bausch and Lomb also supplied financial support for manuscript preparation.

\section{Disclosure}

MP is a consultant for Bausch and Lomb. MR, EL, and PH report no conflicts of interest in this work.

\section{References}

1. Leaming DV. Practice styles and preferences of ASCRS members - 2003 survey. J Cataract Refract Surg. 2004;30(4):892-900.

2. Mentak K. Hydrophobic character and surface stability of hydrophobic acrylic IOLs. Poster presented at: XXVI Congress of the European Society of Cataract and Refractive Surgeon; September 14, 2008; Berlin, Germany.

3. Werner L. Calcification of hydrophilic acrylic intraocular lenses. Am J Ophthalmol. 2008;146(3):341-343.

4. Endophthalmitis Study Group; European Society of Cataract and Refractive Surgeons. Prophylaxis of postoperative endophthalmitis following cataract surgery: results of the ESCRS multicenter study and identification of risk factors. J Cataract Refract Surg. 2007;33(6):978-988.

5. Zheng Q, Yang S, Zhang Y, Wu R, Pang J, Li W. Vitreous surgery for macular hole-related retinal detachment after phacoemulsification cataract extraction: 10-year retrospective review. Eye (Lond). 2012;26(8): 1058-1064.

6. Mamalis N. Intraocular lens biocompatibility. J Cataract Refract Surg. 2002;28(1):1-2.

7. Vasavada AR, Shah A, Raj SM, Praveen MR, Shah GD. Prospective evaluation of posterior capsule opacification in myopic eyes 4 years after implantation of a single-piece acrylic IOL. J Cataract Refract Surg. 2009;35(9):1532-1539.

8. Nishi O, Nishi K, Osakabe Y. Effect of intraocular lenses on preventing posterior capsule opacification: design versus material. J Cataract Refract Surg. 2004;30(10):2170-2176.

9. Buehl W, Findl O. Effect of intraocular lens design on posterior capsule opacification. J Cataract Refract Surg. 2008;34(11):1976-1985.

10. Nixon DR, Woodcock MG. Pattern of posterior capsule opacification models 2 years postoperatively with 2 single-piece acrylic intraocular lenses. J Cataract Refract Surg. 2010;36(6):929-934.

11. Rönbeck M, Zetterström C, Wejde G, Kugelberg M. Comparison of posterior capsule opacification development with 3 intraocular lens types: five-year prospective study. J Cataract Refract Surg. 2009;35(11): 1935-1940.

12. Werner L. Glistenings and surface light scattering in intraocular lenses. $J$ Cataract Refract Surg. 2010;36(8):1398-1420.

13. Christiansen G, Durcan FJ, Olson RJ, Christiansen K. Glistenings in the AcrySof intraocular lens: pilot study. J Cataract Refract Surg. 2001;27(5):728-733.

14. Colin J, Orignac I. Glistenings on intraocular lenses in healthy eyes: effects and associations. J Refract Surg. 2011;27(12):869-875.
15. Colin J, Orignac I, Touboul D. Glistenings in a large series of hydrophobic acrylic intraocular lenses. J Cataract Refract Surg. 2009;35(12): 2121-2126.

16. Colin J, Praud D, Touboul D, Schweitzer C. Incidence of glistenings with the latest generation of yellow-tinted hydrophobic acrylic intraocular lenses. J Cataract Refract Surg. 2012;38(7): 1140-1146.

17. Dhaliwal DK, Mamalis N, Olson RJ, et al. Visual significance of glistenings seen in the AcrySof intraocular lens. J Cataract Refract Surg. 1996;22(4):452-457.

18. Mamalis N. Intraocular lens glistenings. J Cataract Refract Surg. 2012;38(7):1119-1120.

19. Apple DJ, Escobar-Gomez M, Zaugg B, Kleinmann G, Borkenstein AF. Modern cataract surgery: unfinished business and unanswered questions. Surv Ophthalmol. 2011;56(Suppl 6):S3-S53.

20. Packer M, Fry L, Lavery KT, et al. Safety and effectiveness of a glistening-free single-piece hydrophobic acrylic intraocular lens (enVista). Clin Ophthalmol. 2013;7:1905-1912.

21. Tetz MR, Werner L, Schwahn-Bendig S, Batlle JF. A prospective clinical study to quantify glistenings in a new hydrophobic acrylic 1OL. Poster presented at: American Society of Cataract and Refractive Surgery Symposium on Cataract, IOL, and Refractive Surgery: April 3-8, 2009; San Francisco, CA, USA.

22. Packer M. Safety and Visual Outcomes with a 1-Piece Hydrophobic Acrylic IOL in Cataract Patients. American Academy of Ophthalmology Annual Meeting, New Orleans, November 15-19, 2013.

23. Spalton DJ, Ligabue EA, Giordano C. Introducing enVista. Cataract and Refractive Surgery Today Europe. Bryn Mawr, Pa: Bryn Mawr Communications, 2011. Available from: http://cde.frycomm. com/1J4ee6422c13834012.cde. Accessed December 23, 2013.

24. Nanavaty MA, Spalton DJ, Boyce J, Brain A, Marshall J. Edge profile of commercially available square-edged intraocular lenses. J Cataract Refract Surg. 2008;34(4):677-686.

25. Sandoval HP, Fernández de Castro LE, Vroman DT, Solomon KD. Comparison of visual outcomes, photopic contrast sensitivity, wavefront analysis, and patient satisfaction following cataract extraction and IOL implantation: aspheric vs spherical acrylic lenses. Eye (Lond). 2008;22(12):1469-1475.

26. Strenk SA, Strenk LM, Guo S. Magnetic resonance imaging of aging, accommodating, phakic, and pseudophakic ciliary muscle diameters. J Cataract Refract Surg. 2006;32(11):1792-1798.

27. Su PY, Hu FR. Intraindividual comparison of functional vision and higher order aberrations after implantation of aspheric and spherical intraocular lenses. J Refract Surg. 2009;25(3):265-272.

28. Weinand F, Jung A, Stein A, Pfützner A, Becker R, Pavlovic S. Rotational stability of a single-piece hydrophobic acrylic intraocular lens: new method for high-precision rotation control. J Cataract Refract Surg. 2007;33(5):800-803.

29. Packer M, Fine IH, Hoffman RS. Contrast sensitivity and measuring cataract outcomes. Ophthalmol Clin North Am. 2006;19(4):521-533.

30. Guirao A, Redondo M, Geraghty E, Piers P, Norrby S, Artal P. Corneal optical aberrations and retinal image quality in patients in whom monofocal intraocular lenses were implanted. Arch Ophthalmol. 2002;120(9): 1143-1151.

31. Packer M, Fine IH, Hoffman RS, Piers PA. Prospective randomized trial of an anterior surface modified prolate intraocular lens. J Refract Surg. 2002;18(6):692-696.

32. Packer M, Fine IH, Hoffman RS, Piers PA. Improved functional vision with a modified prolate intraocular lens. J Cataract Refract Surg. 2004;30(5):986-992.

33. Mester U, Dillinger P, Anterist N. Impact of a modified optic design on visual function: clinical comparative study. J Cataract Refract Surg. 2003;29(4):652-660.

34. Bellucci R, Scialdone A, Buratto L, et al. Visual acuity and contrast sensitivity comparison between Tecnis and AcrySof SA60AT intraocular lenses: A multicenter randomized study. J Cataract Refract Surg. 2005;31(4):712-717. 
35. Ligabue EA, Giordano C. Aberrometrical Evaluation and Assessing Visual Quality after enVista B+L IOL Implant. Congress of the ESCRS. Milan, Italy: European Society of Cataract and Refractive Surgeons; November 9, 2012.

36. enVista [package insert]. Rochester, NY: Bausch and Lomb, 2012.

37. Miyata A, Yaguchi S. Equilibrium water content and glistenings in acrylic intraocular lenses. J Cataract Refract Surg. 2004;30(8):1768-1772.

38. Shiba T, Mitooka K, Tsuneoka H. In vitro analysis of AcrySof intraocular lens glistening. Eur J Ophthalmol. 2003;13(9-10):759-763.

39. Gregori NZ, Spencer TS, Mamalis N, Olson RJ. In vitro comparison of glistening formation among hydrophobic acrylic intraocular lenses. J Cataract Refract Surg. 2002;28(7):1262-1268.

40. Kato K, Nishida M, Yamane H, Nakamae K, Tagami Y, Tetsumoto K. Glistening formation in an AcrySof lens initiated by spinodal decomposition of the polymer network by temperature change. J Cataract Refract Surg. 2001;27(9):1493-1498.

41. Dogru M, Tetsumoto K, Tagami Y, Kato K, Nakamae K. Optical and atomic force microscopy of an explanted AcrySof intraocular lens with glistenings. J Cataract Refract Surg. 2000;26(4):571-575.

42. Omar O, Pirayesh A, Mamalis N, Olson RJ. In vitro analysis of AcrySof intraocular lens glistenings in AcryPak and Wagon Wheel packaging. J Cataract Refract Surg. 1998;24(1):107-113.

43. Dhital A, Spalton DJ, Boyce JF. Glistenings and visual quality with two hydrophobic intraocular lenses. Posters presented at: American Society of Cataract and Refractive Surgery/American Society of Ophthalmic Administrators Symposium and Conference; Chicago, IL, USA; April 20-24, 2012.

44. International Society for Intraocular Lens Safety [homepage on the Internet]. Executive summary. David J Apple, MD; 2012. Available from: http://www.iolsafety.com/issues-under-discussion/glistenings/letters-ofopinion/128-david-apple.html. Accessed December 18, 2013.

45. Altmann GE, Nichamin LD, Lane SS, Pepose JS. Optical performance of 3 intraocular lens designs in the presence of decentration. J Cataract Refract Surg. 2005;31(3):574-585.

46. Gray R, Hill W, Neuman B, Houtman D, Potvin R. Effects of a blue light-filtering intraocular lens on driving safety in glare conditions. J Cataract Refract Surg. 2012;38(5):816-822.

47. Hoffmann MB, Behrens-Baumann W, Langenbucher A, Reupsch J, Viestenz A. Effect of blue-light filtering on multifocal visual-evoked potentials. J Cataract Refract Surg. 2012;38(1):85-91.

48. Kara-Junior N, Espindola RF, Gomes BA, Ventura B, Smadja D, Santhiago MR. Effects of blue light-filtering intraocular lenses on the macula, contrast sensitivity, and color vision after a long-term followup. J Cataract Refract Surg. 2011;37(12):2115-2119.
49. Schmack I, Schimpf M, Stolzenberg A, Conrad-Hengerer I, Hengerer FH, Dick HB. Visual quality assessment in patients with orange-tinted blue light-filtering and clear ultraviolet light-filtering intraocular lenses. $J$ Cataract Refract Surg. 2012;38(5):823-832.

50. Zhu XF, Zou HD, Yu YF, Sun Q, Zhao NQ. Comparison of blue light-filtering IOLs and UV light-filtering IOLs for cataract surgery: a meta-analysis. PLoS One. 2012;7(3):e33013.

51. Mainster MA, Turner PL. Blue-blocking IOLs vs short-wavelength visible light: hypothesis-based vs evidence-based medical practice. Ophthalmology. 2011;118(1):1-2.

52. Tetz MR, Auffarth GU, Sperker M, Blum M, Völcker HE. Photographic image analysis system of posterior capsule opacification. J Cataract Refract Surg. 1997;23(10):1515-1520.

53. Tetz M, Wildeck A. Evaluating and defining the sharpness of intraocular lenses: part 1: Influence of optic design on the growth of the lens epithelial cells in vitro. J Cataract Refract Surg. 2005;31(11):2172-2179.

54. Werner L, Müller M, Tetz M. Evaluating and defining the sharpness of intraocular lenses: microedge structure of commercially available square-edged hydrophobic lenses. J Cataract Refract Surg. 2008;34(2): $310-317$.

55. Becker KA, Martin M, Rabsilber TM, Entz BB, Reuland AJ, Auffarth GU. Prospective, non-randomised, long term clinical evaluation of a foldable hydrophilic single piece intraocular lens: results of the Centerflex FDA study. Br J Ophthalmol. 2006;90(8):971-974.

56. Nishi O, Nishi K, Osakabe Y. Evaluation of posterior capsule opacification using a new posterior view method in rabbits: single-piece acrylic versus 3-piece acrylic intraocular lens. J Cataract Refract Surg. 2005;31(12):2369-2374.

57. Nishi O, Nishi K. Effect of the optic size of a single-piece acrylic intraocular lens on posterior capsule opacification. J Cataract Refract Surg. 2003;29(2):348-353.

58. Nishi O. [Influence of intraocular lens material and design on the development of posterior capsule opacification]. Ophthalmologe. 2005;102(6):572-578. German [with English abstract].

59. American Academy of Ophthalmology Cataract and Anterior Segment Panel. Preferred Practice Patterns: Cataract in the Adult Eye. San Francisco, CA; American Academy of Ophthalmology; 2011. Available from: http://one.aao.org/preferred-practice-pattern/cataract-in-adulteye-ppp--october-2011. Accessed December 18, 2013.

60. Wilson ME Jr, Trivedi RH. The ongoing battle against posterior capsular opacification. Arch Ophthalmol. 2007;125(4):555-556.

61. Packer M, Fry L, Lavery KT, et al. Safety and effectiveness of a glistening-free single-piece hydrophobic acrylic intraocular lens (enVista). Clin Ophthalmol. 2013;7:1905-1912.
Clinical Ophthalmology

\section{Publish your work in this journal}

Clinical Ophthalmology is an international, peer-reviewed journal covering all subspecialties within ophthalmology. Key topics include: Optometry; Visual science; Pharmacology and drug therapy in eye diseases; Basic Sciences; Primary and Secondary eye care; Patient Safety and Quality of Care Improvements. This journal is indexed on

\section{Dovepress}

PubMed Central and CAS, and is the official journal of The Society of Clinical Ophthalmology (SCO). The manuscript management system is completely online and includes a very quick and fair peer-review system, which is all easy to use. Visit http://www.dovepress.com/ testimonials.php to read real quotes from published authors. 